5. And the work per grain of zinc will be $\frac{75934}{1427^{\circ} 3}=53^{\circ} 2$ or $\frac{1}{3}$ of the maximum duty.

III. Lessen the load so that the velocity of the engine is increased until the current is reduced to one half its original amount, or $2^{\circ} 792$ shown on the galvanometer by a deflection of $70^{\circ} 18^{\prime}$. Then we shall have

I. Heat evolved per hour by the wire $442.64 \times\left(\frac{1}{2}\right)^{2}=$ I 10.66 units.

2. Consumption of zinc per hour $2141 \times \frac{1}{2}=1070^{\circ} 5$ grains.

3. Heat due to $1070^{\prime} 5$ grains, $442 \cdot 64 \times \frac{I}{2}=22 r^{\prime} 32$ units.

4. Therefore the work per hour will be (221'32 - $110 \cdot 66)$ $772=85430 \mathrm{ft}$. lbs.

5. And the work per grain of zinc will be $\frac{85429}{1070^{\circ} 5}=79^{\circ} 8$ or $\frac{1}{2}$ the maximum duty.

IV. Let the load be further reduced until the velocity reduces the current to $\frac{1}{3}$, or to I 86 I 3 shown by a deflection of $6 \mathrm{I}^{\circ} 45^{\prime}$. Then we shall have

I. Heat evolved per hour by the wire $442 \cdot 64 \times\left(\frac{1}{3}\right)^{2}=$ $49^{\circ} 182$ units.

2. Consumption of zinc per hour 214I $\times \frac{1}{3}=713.66$ grains.

3. Heat due to 713.66 grains of zinc $44.2 .64 \times \frac{1}{3}=147.55$ units.

4. Therefore the work per hour will be (I $4755-49^{\circ}$ I 82 ) $772=75940 \mathrm{ft}$. lbs.

5. And the work per grain of zinc will be $\frac{75940}{713.66}=106.4$ or $\frac{2}{3}$ of the maximum duty.

$\mathrm{V}$. Let the load be still further reduced until, with the increased velocity, the current becomes reduced to $\frac{7}{100}$, or to 05584 showing a deflection of $3^{\circ} 12^{\prime}$. Then we shall have

I. Heat evolved per hour by the wire $442.64 \times\left(\frac{\mathrm{I}}{100}\right)^{2}$ $={ }^{\circ} 044264$ of a unit.

2. Consumption of zinc per hour $2 \mathrm{I} 4 \mathrm{I} \times \frac{\mathrm{I}}{100}=2 \mathrm{I}^{\circ} 4 \mathrm{I}$ grains.

3. Heat due to $2 \mathrm{I}^{\circ} 4 \mathrm{I}$ grains of $\operatorname{zinc} 44^{\circ} \cdot 64 \times \frac{\mathrm{I}}{100}=4.4264$ units.

4. Therefore the work per hour will be $\left(4 \cdot 4264-{ }^{\circ} 04426\right)$ $772=3383 \mathrm{ft}$. lbs.

5. And the work per grain of zinc will be $\frac{3383}{21^{\circ} 4 \mathrm{r}}=15^{8}$ or $\frac{98}{100}$ of the maximum duty.

Now suppose that we still further improve our engine by making the stationary magnets twice as powerful. In this case all the figures will remain exactly the same as before, the only difference being that the engine will only require to go at half the velocity in order to reduce the current to the same fraction of its first quantity. The attraction will be doubled, but the velocity being halved no change will take place in the amount of work given out.

In all cases the maximum amount of work per hour is obtained when the engine is going at such a velocity as reduces the current to one half of its amount when the engine is held stationary; and in this case the duty per grain of zinc is one half of the theoretical maximum.

The same principles apply equally well when, instead of employing the machine as an engine evolving work, we do work on it by forcibly reversing the direction of its motion. Suppose for instance we urge it with this reverse velocity until the quantity of current is quadrupled, or becomes $22^{\circ} 386$ indicated by a deflection $87^{\circ} 26^{\prime}$. Then we shall have

I. Heat evolved per hour by the wire $442.64 \times 4^{2}=$ $7082 \cdot 2$ units.

2. Consumption of zinc per hour $2141 \times 4=8564$ grains.

3. Heat due to 8564 grains of zinc $442.64 \times 4=1770^{\circ} 56$ units.

4. Therefore the work per hour will be (1770:56$7082 \cdot 2) 772=-4100432 \mathrm{ft} .1 \mathrm{bs}$.

5. And the work per grain of zinc will be $\frac{-4100432}{8564}$ $=-478.8$ or -3 times the maximum working duty.

The principal reason why there has been greater scope for the improvenmt of the steam engine than for the electro-magnetic engine arises from the circumstance that in the formula $\frac{a-b}{a}$, applied to the steam engine by Thomson, in which $a$ and $b$ are the highest and lowest temperatures, these values are limited by practical difficulties. For a cannot easily be taken above $459^{\circ}+374^{\circ}$ $=833^{\circ}$ from absolute zero, since that temperature gives 12.425 atmospheres of pressure, nor can $b$ be readily taken at less than the atmospheric temperature or $449^{\circ}$ $+60^{\circ}=519^{\circ}$. Also there is much difficulty in preventing the escape of heat; whereas the insulation of electricity presents no difficulty,

I had arrived at the theory of the electro-magnetic engine in 1840 , in which year I published a paper in the 4th Vol. of Sturgeon's Annals, demonstrating that there is "no variation in economy, whatever the arrangement of the conducting metal, or whatever the size of the battery." The experiments of that paper indicate $36 \mathrm{ft}$. lbs. as the maximum duty for a grain of zinc in a Wollaston battery. Multiplying this by 4 to bring it to the intensity of a Daniell's battery, we obtain 144 foot lbs. Here, as in the experiments in the paper on Mechanical Powers of ElectroMagnetism, Steam, and Horses, the actual duty is less than the theoretic; which is owing partly to the pulsatory nature of the current, and partly also to induced currents giving out heat in the substance of the iron cores of the electro-magnets; although these last were obviated as far as possible by using annealed tubes with slits down their sides.

J. P. JOULE

\section{OBFECT TEACHING AND SCIENCE IN AMERICA}

THE following article, reprinted from the Scientific American, will give some idea of the spirit in which the teaching of science is being pursued in the United States:-

"The public are beginning to be awakened to tlie fact that technical education is the education they require, being in accordance with the conditions of modern civilisation; and it is admitted that such technical education must be based upon a foundation of natural knowledge. The principles of the natural sciences must then, for the future, form an essential part of popular education; the only questions are, how far and in what manner are these sciences to be introduced? Whatever is to be the amount taught, educators are agreed that the first steps in natural science, or, in other words, in systematising natural knowledge, are to be taken as early as possible. Early impressions are the deepest, and every child before its school days is already an untrained student of nature. The foundations of technical education should, therefore, be laid in the primary school; but whether commenced thus early or not, the method will always be the same. The child must be encouraged and guided in its natural habits of observing, and it must be led to systematise its observations, connecting them together by a chain of reasoning into groups of related ideas. This method is simply that known as "object teaching ;" and you may as well try to fly without wings, or to teach geography without maps or globes, as to teach natural science without objects and diagrams. There is not a teacher, nowadays, but has heard of this object teaching; there are hundreds who have tried to utilise it; there are 
electrical discharges.-Dr. A. M. Mayer contributes an articie "On the physical condition of a closed circuit contiguous to a permanent and constant Voltaic current; or, on the electrotonic state." The author commences by giving extracts from Faraday's investigations, in which he uses the term electro-tonic state to indicate the condition of a wire in which an electric wave has been induced by the proximity of a conductor through which a constant current was passing. He has endeavoured to obtain some clue of the condition of such a closed circuit by passing through it another electric wave of a constant intensity, and which he ingeniously generated by slipping a flat spiral from the end of a permanent marnet, as described in the num. ber of this journal for November last. Currents thus obtained are found, by means of a delicate reflecting galvanometer, to be practically of the same intensity; for on repeating the experiment several times this produced deflections differing from one another to an extent not greater than $20^{\prime \prime}$. In this manner it was determined that a definite electric current, traversing a metallic circuit in proximity to another traversed by a powerful voltaic current, has the same intensity, whether passed in the same direction as the latter or in a direction opposed to it. The author thinks, however, that a diminution in the velocity of the current ensues, and he intends to continue his experiments in order to settle this question. - This yaper is followed by an abstract of the "Programme for the Observation of Stars of the Ninth Magnitude, undertaken by the German Astronomical Society; an analysis of gahnite from Mine Hill, Franklin Furnace, New Jersey, by G. J. Brush ; and an account of the Observations of the Meteors of November I3 and 14, 1870." - The next article is by Prof. J. Le Conte, "On some Phenomena of Binocular Vision" in continuation of some previous papers. For examining the effects produced on observing oljects with both eyes, the author employs a white plane about twenty inches long and of any convenient width. A notch is cut at one end of the board to enable the operator to place the plane just below the level of the eyes, the notch fitting on the bridge of the nose. By sticking pins on different parts of the board and drawing lines between the pins and the eyes, the phenomena of vision can be investigated. The author points out that when things are looked at with both eyes, the eyes themselves seem to double, two of them combining to form a binocular eye in the middle which looks out between two noses, while the other two are on either side beyond the noses. "This article is well worth perusal.-The next paper is by Sidney I. Smith, "On a Fossil Insect from the Carboniferous Formation of Indiana," and is illustrated by a woodcut representing a wing 2.54 inches long and 0.85 broad, found in the grit quarry near Paoli, Orange County, Indiana, in cutting the stone for making whetstones.-Observations on the Earthquake of October 2oth in North-eastern America have been collected by Mr. A. C. 'I'wining. The area of disturbance extended from New Brunswick in the East to the State of Iowa in the West, and from the lakes of the River St. Lawrence in the North to Cincinnati and Richmond, Va, in the opposite direction. The shock travelled from about E. $6^{\circ} \mathrm{N}$. to about $\mathrm{W}$. $6^{\circ} \mathrm{S}$, at the rate of 160 miles in a minute.The concluding article is by Professor A. E. Verrill, "On some imperfectly known and new Asceidians from New England."

Silliman's Fournal, February, I87I. This number opens with a paper by Dr. A. M. Mayer, "On Observations on the Variation of the Magnetic Declination in connection with the Aurora of October I4, 1870 , with Remarks on the physical connection between changes in area of disturbed solar suriace and magnetic perturbations." The aurora was first noticed at 6.30 P.M. on Octoher I4, and the magnetic observations commenced at 6. 35 P.M. and were continued till Io P.M. The mean declination being represented by $0^{\circ}$, at 6.35 P.M. the declination was $5^{\prime} \cdot 70 \mathrm{~W}$. and at 6.56 P.M. $18^{\prime} .37 \mathrm{~W}$. The magnet then rapidly moved towards the E., and at 7.46 the declination was $2 \mathrm{I}^{\prime} \cdot 94 \mathrm{E}$. The motion now became westerly, and at $7.57 \frac{1}{2}$ P.M. the reading was $32^{\prime} \cdot \mathrm{Ig}$ W. There was next a rapid easterly movernent till $8.5 \frac{1}{2}$ P.M., when the reading was $10^{\circ} 42 \mathrm{E}$, deep rough streamers flashing up in the N.N.W. There was another deviation to $4^{\prime} \cdot 55$ W. at 8. IO P.M., after which the needle passed to the east of the neutral line, and, after several oscillations, reached the maximum easterly deviation of $22^{\prime} .52 \mathrm{E}$. at 9.10 P.M. The author makes daily observations of the spots on the sun, and remarks on the cunnection existing between their appearance and magnetic disturbances. He points out the necessity of establishing several stations, where daily photographs of the sun may be taken.The next communication is the first part of a series of "Notes on Granite Rocks," by T. Sterry Hurst, LL.D., F.R.S. This paper is continued in the numbers of the Journal for March, and its extraction may perhaps be more conveniently deferred until the whole of it has appeared.-Mr. E. D. Cope contributes a short note on "Siredon Metamorphoses."-This is followed by a note by Professor G. B. Andrews, "On Lower Carboniferous Limestones in Ohio," and the conclusion of Professor Verrill's "Descriptions of Ascidians from New England."--This number also contains a " Memoir of Professor Graham, by Professor J. N. Cooke, and a "Description of the Auroral belt of October 24-25, as observed at New Haven.

\section{SOCIETIES AND ACADEMIES}

\section{LONDON}

Royal Institution of Great Britain, April 3.-Mr. Warren De la Rue, F.R.S., vice-president, in the chair. Mr. William Cubitt, Mr. William Gould, Mr. Robert Hannah, Mr. John Henry Mackenzie, Rev. John Macnaught, M.A., Mr. Joseph Reynolds Masters, Mr. George Borwick Robertson, F.C.S., and Mr. George Wilson, were elected members of the Royal Institution. The special thanks of the members were returned for the following donation to "The Fund for the Promotion of Experimental Researches :"-Mr. T. Williams Helps (6th donation), Io!.

Entomological Society, April 3. Mr. A. R. Wallace, president, in the chair.-The Secretary exhibited drawings of Chinese Lepidoptera, beautifully executed by Mr. Holds. worth, of Shanghai. - Mr. F. Smith exhibited several examples of gynandromorphous Aculeata Hymenoptera, including Authoploora acervorum, Andrenta nitida, Nomada baccata, and Apis mellifica, the latter combining the characters of male and workers. Mr. Lewis referred to the damage occasioned to books by Lepisma saccharina, which fed upon the paste of the bindings, and caused them to fall to pieces. Mr. Lewis also read a paper on the arrangement of British Lepidoptera, as adopted by various authors and compilers of catalogues, and he deprecated very strongly the constant changes in arrangement and nomenclature that are being made, the writers in many cases failing to give any reasons for such changes.

Anthropological Institute, April 3.--Sir John Lubbock, Bart., president, in the chair. Messrs. F. W. Rudler and Archibald Hamilton were elected members. Mr. Boyd Dawkins, yread a paper "On the results cbtained by the Settle Cave Exploration Committee." Victoria Cave, near Settle, in Yorkshire, is situated half-way up a cliff 200 feet hi $h$, and consists of a series of large chambers and passages, and has from time to time furnished to its explorer, Mr. Jackson, a remarkable collection of ornaments and implements of bronze, iron, and bone, along with pottery and broken remains of various animals, viz., red-deer, roebuck, pig, horse, sheep, goat, badger, fox, and dog. Fragments of Samian ware and coins of Trajan prove that the stratum in which they were discovered was accumulated subsequently to the Roman invasion. The numerous articles and bones were described in full detail. The author concluded that the cave was first inhabited by a barbarous Neolithic family, and, lastly, after a long interval, by Roman provincials, or possibly their descendants fleeing away from the arms of an invader. -A paper by Dr. Barnard Davis, F.R.S., was read, "On some recent Anatomical" Writings bearing upon Anthropology, by Prof. Luigi Calori, of Bologna ;" principally on the magnificent memoir of that anatomist, "Del Cervello, nei due tipi Brachicefalo e Dolicocefalo Italiani," lately published. That work is divided into four parts:-I. On the figure of the Brain in the two types. 2. The cerebral convolutions; their various aspect and their variety or anomalies. 3. On the weight of the brain in the two Italian types, brachycephalic and dolichocephalic. 4. On the extension of the cerebral superficies in the two Italian types. The second article goes into a thorough examination of the cerebral convolutions and the varieties they present.-Mr. A. L. Lewis contributes a paper "On the builders of the Megalithic Monuments of Britain." A special general meeting of the members of the Institute was held previously for the purpose of adopting the regulations proposed by the Council. Trustees of the Institute were elected, viz., Sir John Lubbock, Eart., president; J. W. Flower, treasurer; and the Rev. Dunbar J. Heath, M.A. 